\title{
1 Co-transport of Gold Nanospheres with Single-walled Carbon Nanotubes in Saturated Porous Media
}

3

\author{
Submitted \\ to \\ Water Research \\ March9, 2016
}

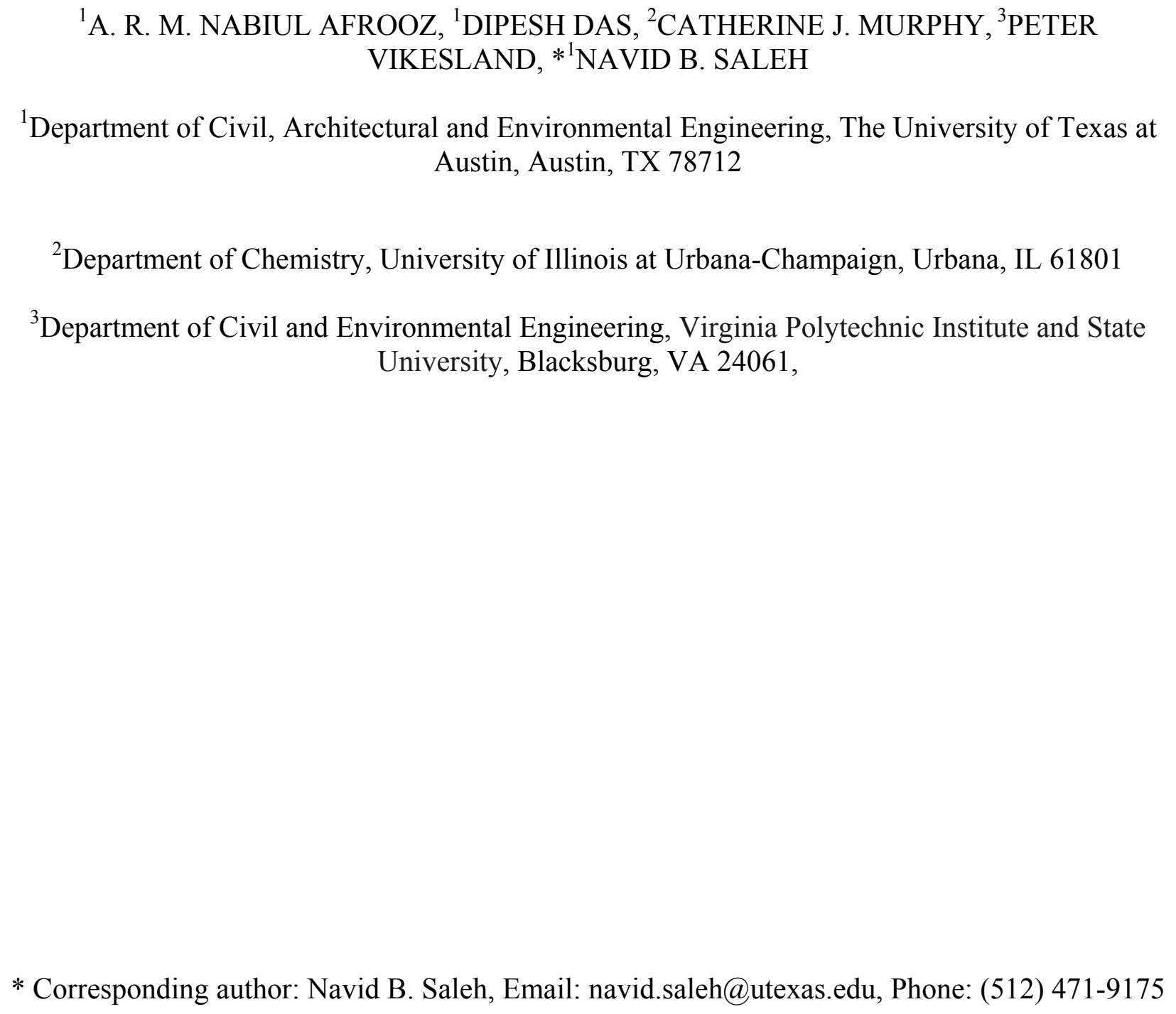

${ }^{1}$ Department of Civil, Architectural and Environmental Engineering, The University of Texas at Austin, Austin, TX 78712

${ }^{2}$ Department of Chemistry, University of Illinois at Urbana-Champaign, Urbana, IL 61801

${ }^{3}$ Department of Civil and Environmental Engineering, Virginia Polytechnic Institute and State University, Blacksburg, VA 24061,

* Corresponding author: Navid B. Saleh, Email: navid.saleh@utexas.edu, Phone: (512) 471-9175 
44 Porous media transport of engineered nanomaterials (ENMs) is typically assessed in a controlled 45 single-particulate environment. Presence of a secondary particle (either natural or engineered) in 46 the natural environment though likely, is rarely taken into consideration in assessing ENMs' 47 transport behavior. This study systematically assesses the effect of a secondary ENM (i.e., 48 pluronic acid modified single-walled carbon nanotubes, PA-SWNTs) on a primary particle (i.e., 49 gold nanospheres, AuNSs)transport through saturated porous media under a wide range of 50 aquatic conditions (1-100 mM NaCl). AuNS hetero-dispersions (i.e., with PA-SWNTs) are 51 transported through saturated sand columns, and the transport behavior is compared to AuNS-

52 only homo-dispersion cases, which display classical ionic strength-dependent behavior. AuNS

53 hetero-dispersion, however, is highly mobile with little to no ionic strength-dependent effects.

54 This study also assesses the role of pre-coating of the collectors with PA-SWNTs on AuNSs' 55 mobility,therebyelucidating the role played by the order of introduction of the secondary 56 particles. Pre-existence of the secondary particles in the porous media shows enhanced filtration 57 of primary AuNSs. However, the presence of natural organic matter (NOM) slightly increases 58 AuNS mobility through PA-SWNT coated sand at $10 \mathrm{mM}$ ionic strength. The study results 59 demonstrate that the presence and order of addition of the secondary particles strongly influence 60 primary particles' mobility. Thus ENMs can demonstrate facilitated transport or enhanced 61 removal, depending on the presence of the secondary particulate matter and background solution 62 chemistry.

65 Keywords:Co-transport; porous media; gold nanoparticles; single-walled carbon 66 nanotubes;pluronic 


\section{Introduction}

69 Increased use of engineered nanomaterials (ENMs) makes their environmental release highly

70 likely whether the release is intentional as remedial agents, accidental from manufacturing

71 processes, or inevitable at the end of life of ENM-containing products(Köhler et al. 2008,

72 Nowack et al. 2012), highly likely. Regardless of routes of release and exposure(Khin et al.

73 2012, Köhler et al. 2008) sediments and porous subsurface have beenidentified as likely

74 environmental sinks for ENMs(Gottschalk and Nowack 2011), in which the ENMs undergo

75 subsequent transport and transformation(Lowry et al. 2012). Fate and transport, the primary

76 process controlling ENM exposure and risk, is at the center of the nano-environmental health and

77 safety (nano-EHS) research(Petosa et al. 2010), which devotes most of its efforts todetermining

78 appropriate fate descriptors (deposition rate and efficiency or transport distances) withsingle-

79 particle breakthrough studies(Petosa et al. 2010, Xin et al. 2016)or by studying deposition onto

80 polished crystal surfaces(Chang and Bouchard 2013, Quevedo and Tufenkji 2009). Although a

81 reliable prediction of ENM transport is the ultimate goal of nano-EHS studies, most, if not all,

82 are performed in clean and controlled environmental platforms.

State-of-the-art ENM transport studies have systematically evaluated the effects of

84 various material properties and background chemistries of a wide set of materials (Petosa et al.

85 2012), e.g., fullerenes $\left(\mathrm{nC}_{60}\right)$, carbon nanotubes (CNTs), nano-scale zero-valent iron (nZVI),

86 titanium dioxide $\left(\mathrm{TiO}_{2}\right)$, zinc oxide $(\mathrm{ZnO})$, and silver nanoparticles (AgNPs). Theinfluence of

87 solution chemistry [pH and Ionic Strength(Godinez and Darnault 2011), organic matter(Thio et

88 al. 2011)], ENM characteristics [size and size distribution(Phenrat et al. 2009),

89 concentration(Phenrat et al. 2009), shape(Afrooz et al. 2013b), surface charge(El Badawy et al. 
2013), synthesis method(Chowdhury et al. 2012a), surface coating(Tripathi et al. 2011), and magnetic properties(Hong et al. 2009)], collector properties [grain size distribution(Mattison et al. 2011) and flow conditions (Cai et al. 2015)] on ENMs' mobility have also been reported. In addition to the aforementioned experimental investigations, efforts have been made to predict and validate ENM transport theoretically by employing clean-bed filtration theory (CFT)(He et al. 2009). However, experimental and theoretical studies of ENMs in homogeneous and single particulate systems have limited transferability to the natural environment in the presence of natural particles and other ENMs(Hotze et al. 2010).

Appreciating the need for assessment of environmental complexities, numerous studies have been conducted to delineatethe effects of physical [i.e., surface roughness(Song and Elimelech 1994) and shape(Saiers and Ryan 2005)] and geochemical [i.e., surface charge(Song et al. 1994), surface coating(Joo et al. 2009), and mineralogical compositions(Kim et al. 2012)] heterogeneities of the collectors on ENM transport. Furthermore, the effectof pre-coating(Joo et al. 2009, Tong et al. 2010) the collector surfaces with natural organic matter (NOM), clay, or biofilm has also been evaluated, where ENM mobility is reported to decrease due to the competition between the ENMs and the NOMs for available attachment sites or to increase due to the availability of increased surface sites of the secondary particle coated collectors for NM deposition(Chowdhury et al. 2012a, Tong et al. 2010).The altered nanomaterials transport behavior in the presence of secondary entities necessitates further studies to assess the effects of environmental complexities on porous media transport of ENMs.

Altered interfacial interaction of the ENMs may also result from theco-existence of multipleparticulate entities in the columninfluent suspension (Afrooz et al. 2013a, Cerbelaud et al. 2008, Huynh et al. 2012). These studies were performed with aquatic suspensions to 
113 understand their aggregation behavior under certain ionic strength conditions, but do not provide 114 any information regarding the sub-surface transport processes of ENMs. ENM co-transport 115 studies are needed to better understand of the influences of secondary entities; i.e., ENMs, bio116 particles, or natural nanoparticles (co-dispersed with the primary ENM or pre-deposited on 117 collector surfaces), on the transport of the primary particles through porous media.Thus far, 118 ENM co-transport literature primarily assessed the effectsof bacterial presence on ENM transport 119 behavior; e.g., $\mathrm{TiO}_{2}$ transport was observed to have enhanced in a co-transport scenario compared 120 to that of $\mathrm{TiO}_{2}$-only case (Chowdhury et al. 2012a, Wang et al. 2012). Reduced bacterial 121 mobility in the presence of CNT has also been reported(Yang et al. 2013a) at an elevated ionic 122 strength (25-100 mM). Additionally, the effect of natural nanomaterials (NNM) on ENM 123 transport has been reported (Wang et al. 2015):goethite nanoparticle showed an enhanced 124 mobility of nano-hydroxyapatite at circumneutral $\mathrm{pH}$ due to heteroaggregation between the two 125 particles. Such evidences suggest that ENM transport through porous media is strongly 126 influenced by the presence of a secondary particulate entity, the likely mechanism beinghigher 127 collision and facilitated filtration.

128 However, transport studies with multiple ENMs are scarce in ENM fate and transport 129 literature. To-date, only two such studies have been reported: $\mathrm{TiO}_{2}$ transport with multiwalled 130 carbon nanotubes (Wang et al. 2014) and co-transport of $\mathrm{TiO}_{2}$ and $\mathrm{nC}_{60}(\mathrm{Cai}$ et al. 2013). These 131 studies reported significant differences in the mobility of the primary $\mathrm{TiO}_{2}$ in singular and binary 132 matrices (in the presence of secondary $\mathrm{nC}_{60} \mathrm{~s}$ or $\mathrm{CNTs}$ ) with strong $\mathrm{pH}$ and ionic strength 133 dependence. Similarly, when $\mathrm{TiO}_{2}$ was used as a secondary particle, transport of CNTs decreased 134 under all examined conditions. However, both of these studies used matrices in which primary 135 and secondary particles would undergo simultaneous deposition at higher ionic strength (i.e., 
136 representing brackish or saline condition); thus they preclude enumeration of underlying 137 transport mechanisms over a wide range of ionic strength. Therefore, contribution of the 138 reported studies is restricted to low ionic strength $(0.1-10 \mathrm{mM})$ conditions with limited 139 environmental relevance.To summarize, mechanistic co-transport studies appear to be a 140 persistent data gap in the ENM fate and transport literature, and the role of a wide range of 141 environmentally relevant ionic strength conditions, presence of NOM, and the order of addition 142 of the secondary particles need to be systematically assessed. nanospheres (AuNSs), in the presence of a well-characterized secondary ENM, i.e., single145 walled carbon nanotubes (SWNTs). This study contributes to addressing the existing data gaps 146 by providing a mechanistic understanding of ENM co-transport behavior over a wide range (1$147100 \mathrm{mM}$ ) of ionic strength for a new ENM duo (AuNS-SWNT). In order to mechanistically 148 assess the filtration mechanisms, especially at elevated ionic strengths, inherent SWNT-SWNT 149 interaction is eliminated via nonionic pluronic acid (PA) functionalization(Afrooz et al. 2013a). 150 A range of PA concentrations is utilized to generate PA-SWNTs with desirable stability, i.e., 151 highly stable suspensions are used for co-transport studies, whereas, SWNTs with lower stability 152 are used to pre-coat the collector surfaces. Co-transport under a wide range of ionic strength (1$153100 \mathrm{mM} \mathrm{NaCl}$ ) is studied and compared with primary AuNS transport. Theeffect of NOM on 154 AuNS transport is also monitored for typical groundwater conditions (i.e., $10 \mathrm{mM}$ total ionic 155 strength). This is a first-of-its-kind study to mechanistically assess co-transport of AuNSs (in the 156 presence of another ENM) over a wide range of ionic strengths. The results from this study can 157 be considered the initial step to attain a more reliable assessment of ENM co-transport through 158 porous media in cases of multiple ENMs' presence in an aquatic environment. 


\section{Materials and Methods}

\subsection{Preparation of AuNS Suspensions}

163

164

165

166

167

168

169

170

171

172

173

174

175

176

177

178

179

180

181

Poly (acrylic acid) or PAA-coated AuNS suspension at a concentration of $50 \mathrm{mg} / \mathrm{L}$ was procured from Nanopartz Inc. (Loveland, CO). The supplier reported $10 \mathrm{~nm}$ nominal diameter for the AuNSs. Procured AuNSs were diluted 4 times to achieve a concentration of $12.5 \mathrm{mg} / \mathrm{L}$ for all transport experiments.

\subsection{Preparation of PA-SWNTs}

Dry SWNTs, produced by high-pressure carbon monoxide disproportionation or HipCO method(Bronikowski et al. 2001) was obtained from Tubes at Rice (Houston, TX). The supplier reported that average diameter and length of the SWNTs were $1.03 \mathrm{~nm}$ (a range of 0.7-1.45 nm) and $0.93 \mu \mathrm{m}$ (a range of $0.1-2.6 \mu \mathrm{m}$ ), respectively. Commercially available pluronic acid (PA) F-127 was obtained from Sigma Aldrich (St. Louise, MO); and 0.02, 0.1, 1, and 5\% (w/v) PA solution was prepared using filtered $(0.45 \mu \mathrm{m}$ inorganic membrane filters, VWR international LLC, Radnor, PA) deionized (DI) water (Millipore, Darmstadt, Germany). The PA solutions were prepared by magnetic stirring for $1 \mathrm{~h}$ at room temperature.

$10 \mathrm{mg}$ of procured SWNTs was added to $100 \mathrm{~mL}(0.02,0.1,1$, and $5 \%)$ of PA solution and sonicated in an ice bath for $1 \mathrm{~h}$ employing an S-4000 ultrasonicator (Misonix, Inc. Farmingdale,NY) at a controlled input energy of 100-105 kJ. The sonicated samples were quiescently left aside for $24 \mathrm{~h}$ and the supernatant was decanted and centrifuged at $12000 \times \mathrm{g}$ for $1 \mathrm{~h}$ with a Beckman Coulter (Brea, CA) centrifuge. The supernatant of the centrifuged samples was then decanted and used for subsequent experiments. 


\subsection{Solution Chemistry} 195 the dark at $4{ }^{\circ} \mathrm{C}$.

All transport experiments were performed in the presence of monovalent $\mathrm{NaCl}$ at $1,10,30$, and $100 \mathrm{mM}$ concentrations. A $5 \mathrm{M} \mathrm{NaCl}$ stock solution (BDH Chemicals) was purchased from VWR (Radnor, PA) and diluted with filtered DI water to obtain the solution at appropriate ionic strength. The $\mathrm{pH}$ of the salt solutions was left unadjusted (ambient) and determined to be $6.56 \pm$ 0.04. Suwannee River humic acid or SRHA (Standard II, 2S101H, International Humic Substances Society, St. Paul, MN) at $2.5 \mathrm{mg}$ TOC/L was used as the representative NOM. SRHA solution was prepared by dissolving $5 \mathrm{mg}$ of dry powder in $100 \mathrm{~mL}$ DI water and by magnetically stirring for $30 \mathrm{~min}$. The solution was then filtered through $0.45 \mu \mathrm{m}$ syringe filters (PES filters, Thermo Scientific, Pittsburgh, PA). TOC equivalence was used and measured with a TOC analyzer (TOC-VCSH, Shimadzu Corp., Japan). The SRHA stock solution was stored in

\subsection{Physicochemical Characterization}

Physical morphology of the AuNSs and SWNTs was characterized using a JEOL 2010F Transmission Electron Microscope (TEM) at the Texas Materials Institute. Copper-carbon TEM grids were prepared with ENM suspensions at desired particle concentrations and dried at $60{ }^{\circ} \mathrm{C}$ for 15 min. Bright field imaging and high-resolution (HR) microscopy techniques were utilized to investigate the particle size and shape.

DLS was employed to characterize the size of the ENMs in the experimental matrices. Details of the DLS technique havebeen described elsewhere(Saleh et al. 2008). Briefly, $2 \mathrm{~mL}$ ENM suspension was added into a clean borosilicate glass vial under appropriate solution 
205 chemistry. A $632.8 \mathrm{~nm}$ laser (ALV CGS-3 goniometer system, Langen, Germany) shone 206 through the vial and scattered light was detected at $90^{\circ}$ and converted to hydrodynamic radii 207 (HR) employing an auto-correlator and cumulant analysis. HR data were collected every $10 \mathrm{~s}$ for 208 a 30 min duration.

To assess and confirm the chemical identity of the AuNS, an Agilent 8454 UV-vis 210 spectrophotometer (Santa Clara, CA) was used. AuNS suspensions were prepared and injected 211 to a flow through cell of $300 \mu \mathrm{L}$ volume. Spectral response was collected for the entire UV and 212 visible range (200-1100 $\mathrm{nm})$.

\subsection{Electrokinetic Characterization}

214 Electrophoretic mobility (EPM) of the ENMs in their homogeneous and heterogeneous 215 dispersion states were evaluated using a Malvern Zetasizer (Malvern Instruments Ltd., 216 Worcestershire, $\mathrm{UK}$ ) at $\mathrm{pH} 6.7 \pm 0.1$ and at a temperature of $20{ }^{\circ} \mathrm{C}$. For each condition, $800 \mu \mathrm{L}$ 217 sample was injected into the disposable capillary cell (DTS 1070) ensuring that the sample 218 wasbrought in contact with the electrodes without any introduction of air bubbles. Four different 219 cells were used for AuNS, PA-SWNT (0.02\%), PA-SWNT (5\%), and AuNS-PA-SWNT (5\%) 220 suspensions. Cells were flushed 10 times with DI water between each measurement. A total of 3 221 replicates were taken for every measurement to ensure reproducibility. $\mathrm{NaCl}$ concentrations of $2221,10,30$ and $100 \mathrm{mM}$ were considered for all the suspensions. Experiments investigating the 223 effects of NOM were performed at $10 \mathrm{mM}$ ionic strength conditions.

\subsection{Column Experiments}

$2252.5 \mathrm{~cm}$ diameter and $10 \mathrm{~cm}$ long, Kontes Glass columns (Kimble Chase, Vineland, NJ) were 226 packed with Ottawa sand (Fischer Scientific, Waltham, MA). The 20-30 mesh sand was 227 carefully washed and cleaned following a detailed cleaning protocol described elsewhere(Saleh 
et al. 2007). In brief, the Ottawa sand was saturated in DI water overnight and then boiled for 10 min followed by bath sonication and subsequent washing to remove impurities and colloids. Thesonication procedure involved multiple sonication-rinsing cycles (10 min sonication and 2 min rinsing). Each sonicated batch was rinsed three times and the supernatant was decanted prior to the next cycle of sonication. In total, 15 such sonication-rinsing cycles were used to remove all loosely bound colloids and impurities. The cleaned sand was then soaked overnight in concentrated hydrochloric acid $(\mathrm{HCl})$ to remove any metallic impurities. The sand collectors were then washed with DI until the $\mathrm{pH}$ reached 6.5; this was followed by an additional cycle of soaking with $50 \mathrm{mM} \mathrm{CaCl}$.An additional 5 cycles of sonication-rinsing were performed to remove tightly bound colloids fromthe collector surfaces. Such extensive cleaning of the sand was necessary to de-convolute the breakthrough signal from any potential release of pre-existing colloids that are typically present in the as-received sand. The cleaned sand was then dried at 80 ${ }^{\circ} \mathrm{C}$ and stored in an airtight container. The cleaned sand was re-sieved with $20-25$ mesh sieve, to attain a narrower grain size of 707-841 $\mu \mathrm{m}$.

The Kontes columns were dry-packed(Jaisi et al. 2008) following a layer-by-layer packing process, where 1-cm layers were poured in and compacted with a wooden bar. A vibrator was used to ensure uniform packing and eliminate stratification. Carbon dioxide gas was made to flowthrough the column for 20 minutes to remove all air from the pore spaces. The column was saturated by pumping DI water (Figure S1) for $8 \mathrm{~h}$ via an Ismatec precision variablespeed peristaltic pump purchased from IDEX Inc. (Wertheim, Germany). Porosity of the packed beds was determined gravimetrically by weighing the column before and after DI saturation, and was found to be $0.376 \pm 0.013$. After the saturation ofthe column, tracer studies were performed using 4 pore volumes (PVs) of lithium bromide ( $\mathrm{LiBr}$ ) solution. The tracer was monitored 
251 continuously at 197nm wavelength using aUV-vis detector(Agilent Technologies, Santa Clara,

252 CA). Prior to the introduction of the ENMs, the packed column was flushed with at least 4 PVs

253 of appropriate background solution. The approach velocity of the tracer and the carrier solution

254 was adjusted to $0.003 \mathrm{~cm} \mathrm{~s}^{-1}$ (equivalent to a volumetric flow rate of $1 \mathrm{~mL} \mathrm{~min}{ }^{-1}$ ). ENMs were

255 then introduced at the same background electrolyte concentration as a finite pulse (4PVs). The

256 pulse was followed by the injection of the respective electrolyte solution for 4 more PVs.

257 Subsequent injection of DI water was performed to monitor ENM release. For each new

258 experiment, a cleaned and newly packed column was used.

259 The effluent concentration was measured using pre-established calibration curves (Figure

260 S2) for AuNS, PA-SWNTs, and AuNS-PA-SWNT hetero-dispersions. Dilution factors of 2, 4,

2616 , and 8 to the stock AuNS suspensions were used to obtain a calibration curve at $517 \mathrm{~nm}$ using a

262 flow through cell (Agilent Technologies, Santa Clara, CA) of $300 \mu \mathrm{L}$ volume. For PA-SWNTs,

$2635,10,20,40$ dilution factors were used to develop a calibration curve at $235 \mathrm{~nm}$. Calibration

264 curves obtained for the AuNS and PA-SWNTs resulted in $\operatorname{anR}^{2}$ value of 0.9999 for both cases

265 (Figure S2).A calibration curve was also obtained for AuNS-PA-SWNTs hetero-dispersion, at

266 their characteristic wavelength of $517 \mathrm{~nm}$, which resulted in an $\mathrm{R}^{2}$ value of 0.9998 (Figure S2).

267 For the ENM transport studies, AuNS and PA-SWNTs $(0.02 \%, 0.1 \%, 1 \%$, and 5\%) were flowed

268 through the saturated column under varying ionic strength $(1-100 \mathrm{mM} \mathrm{NaCl})$. The concentration

269 of the column effluent was continuously monitored every $15 \mathrm{~s}$ (approx. $0.02 \mathrm{PV}$ ) for the entire

270 duration of the experiment.At least one replicate run (through a freshly packed column) was

271 performed under each ionic strength condition.

272

Co-transport experiments were performed flowing a hetero-dispersion of AuNS-SWNT

273 (at a mass ratio of 1:5 for SWNT:AuNS). Also, a sequential flow of PA-SWNT and AuNS was 
274 made, where 4 PV of PA-SWNTswas made to flowthrough the sand-packed column under a

275 certain ionic strength (to pre-coat the collector surfaces) followed by 4 PV of AuNS injectionat

276 the same ionic strength. Co-transport and sequential-transport experiments were carried out at

277 electrolyte concentrations identical to the "AuNS-only"cases.

\section{Results and Discussions}

\subsection{Morphological and Chemical Properties}

280

281

282

283

284

285

286

287

288

289

290

291

292

293

294

295

296

Figure S3 presents representative high-resolution transmission electron micrographs of AuNS and SWNTs. AuNSs have spherical morphology with an average diameter of $12.9 \pm 1.7 \mathrm{~nm}$ (Figure S3a). SWNTs are found to be well-dispersed within the dispersion media (Figure S3b). A significant number of dark spots are observed in the PA-SWNT images, which are probablymetal catalysts used for SWNT synthesis. Elemental analysis (EDS) of the samples confirms the presence of iron $(\mathrm{Fe})$ catalysts in the sample.

The chemical signature of the AuNS and surface properties of the PA-SWNTs were further evaluated using UV-vis and Raman spectroscopy, respectively.The AuNSs (16.67 mg/L) show a characteristics peak at $517 \mathrm{~nm}$ (Figure S4a) with an absorbance of 0.347 a.u.(Soejima et al. 2011). Raman spectroscopy of the SWNTs confirms the presence of characteristics defect or $\mathrm{D}$ and graphitic or G peaks at 1330 and $1595 \mathrm{~cm}^{-1}$, respectively (Figure S4b). The attenuation of the $\mathrm{D} / \mathrm{G}$ ratio of SWNTs from 0.5580 to 0.1778 for pristine and PA-SWNTs (dispersed in 5\% PA), respectively,indicates effective surface coverage of PA. Similar attenuation of D/G has previously been reported in the literature for such non-covalent functionalization (Georgakilas et al. 2002).

The DLS-measured average hydrodynamic radii (HR) of AuNSs and PA SWNTs in DI waterare $18.9 \pm 1.2$ and $180.5 \pm 15.8 \mathrm{~nm}$, respectively (Figure S5). However, the hetero-dispersion 
of AuNS-SWNT shows an average HR of $41.4 \pm 10.4 \mathrm{~nm}$. The reduction of particle size in the hetero-dispersion is likely the result of the averaging of smaller AuNSs with a lower concentration of relatively larger sized PA-SWNTs, as the CONTIN algorithm provides overall intensity-averaged particle sizes over the measurement period.

\subsection{Electrokinetic Properties}

ENMs demonstrate a decreasing trend in the absolute values of the EPMs with increase in electrolyte concentration (Figure S6), supporting the classical electrokinetic behavior of charged particles(Jaisi et al. 2008, Saleh et al. 2007). EPMs of AuNSs decrease from -(2.78 \pm 0.18$)$ to $(1.63 \pm 0.23) \times 10^{-8} \mathrm{~m}^{2} \mathrm{~V}^{-1} \mathrm{~S}^{-1}$ for an increase in $\mathrm{NaCl}$ concentration 1 to $100 \mathrm{mM}$. The origin of the negative surface potential is likely from the PAA polyelectrolyte (negative carboxyl moieties) coatings and is consistent with previously reported literature values(Afrooz et al. 2013a, Afrooz et al. 2013b, Fresnais et al. 2013). However, EPMs for both 0.02\% and 5\% PASWNTs do notvary substantially, i.e., $-(0.35 \pm 0.03)$ and $-(0.29 \pm 0.03) \times 10^{-8} \mathrm{~m}^{2} \mathrm{~V}^{-1} \mathrm{~S}^{-1}$ to $-(0.03 \pm 0.03)$ and $-(0.03 \pm 0.02) \times 10^{-8} \mathrm{~m}^{2} \mathrm{~V}^{-1} \mathrm{~S}^{-1}$, respectively for the same increase in $\mathrm{NaCl}$ concentration. Since PA is a nonionic polymer, theselow values of EPMs confirm that effective coating of the SWNT surfaces occurs with these polymers, and that the likely stabilization has occurred from steric interaction between the sorbed polymer layers(Moore et al. 2003, Vaisman et al. 2006). For the hetero-dispersion of AuNSs and 5\% PA-SWNTs, changes in $\mathrm{NaCl}$ concentration from 1 to $100 \mathrm{mM}$ result in an EPM decrease from $-(1.02 \pm 0.23)$ to $-(0.18 \pm$ $0.02) \times 10^{-8} \mathrm{~m}^{2} \mathrm{~V}^{-1} \mathrm{~S}^{-1}$. These values are intermediate to the EPM values of AuNS and PASWNT homo-dispersions. Since electrophoresis is an optical technique that monitors average scattering from particle diffusion under an electric field, the overall reduction in EPM valuesfor 
319 the hetero-dispersion may be due to the averaging of low EPM nonionic PA-coated SWNTs with 320 the higher EPM AuNSs.

\subsection{Transport of AuNS Homo-dispersions}

324 Transport behavior of the AuNS homo-dispersions is presented in Figure 1 as a function of $\mathrm{NaCl}$

325 concentrations. Background electrolytes significantly influence the AuNS transport through the 326 sand column, as their mobility decreases with an increase in electrolyte concentration. The \% 327 eluted is estimated (by numerical integration) as $96.9 \pm 4.6 \%$ of the influent mass for $1 \mathrm{mM} \mathrm{NaCl}$ 328 case. Such negligible deposition at lower ionic strength indicates strong electrostatic repulsion 329 between AuNSs and collector surfaces. Other mechanisms of filtration, i.e., straining are not 330 significant, because the size ratio of the AuNS and the sand grains (i.e., 0.0003) is much lower 331 than the literature-reported favorable colloids/media diameter ratio (i.e., 0.005) for physical 332 filtration(Bradford et al. 2004). AuNS mobility is the lowest in the presence of $100 \mathrm{mM} \mathrm{NaCl}$ 333 with a breakthrough plateau of $0.49 \pm 0.03$ and elution of $40.0 \pm 2.3 \%$. The decreasing trend of the 334 elution of the AuNS homo-dispersion through the sand column with increasing ionic strength can 335 be explained by the corresponding reduction in electrostatic double layer interaction as is evident 336 inFigure S6. These results corroborate similar findings(Jaisi et al. 2008, Saleh et al. 2007) for 337 other negatively charged ENMs, e.g., CNT and nZVI particles. 339 through the column (Figure S7). At low ionic strength, (i.e., $1 \mathrm{mM} \mathrm{NaCl}$ ) no detachment or 340 release of the deposited AuNSswas observed (hence not shown in Figure S7). A numerical 341 integration (using discretized trapezoids) of the release curves suggest that $57 \%, 87 \%$, and $86 \%$ 
342 of the retained material has been released when the solution chemistry changed to DI from 10 ,

34330 , and $100 \mathrm{mM} \mathrm{NaCl}$, respectively. The shape of the breakthrough and the increasing release

344 percentages with increased salt concentrations suggest that the AuNS deposition onto the sand 345 surface is primarily electrostatic and is at the secondary minima. The observed detachments of 346 the particles can be attributed to removal of particles from the secondary energy well as observed 347 earlier for other ENMs, e.g., SWNTs and nano cerium dioxide (Jaisi et al. 2008, Li et al. 2011).

\subsection{Transport of PA-SWNT Homo-dispersions}

349 SWNTs, dispersed in a wide range of PA concentrations $(0.02-5 \%)$, were injected through sand 350 columns at low $(1 \mathrm{mM})$ and high $(100 \mathrm{mM})$ electrolyte conditions. At low ionic strength, the 351 effect of PA functionalization on SWNT mobility is negligible (Figure S8). Even though the 352 EPMs of the PA-SWNTs slightly decrease (Figure S6) with an increase in the amount of PA 353 used in dispersion, the breakthrough plateau and retention percentages of the SWNTs are similar 354 for the entire range of PA. The average retention of the PA-SWNTs at $1 \mathrm{mM} \mathrm{NaCl}$, for the 355 entire range (i.e., $0.02-5 \%$ ) of PA, is $6.9 \pm 1.5 \%$ (Figure S8). Filtration of PA-SWNTs at low 356 ionic strength with no detectable releases can be attributed to the physical removal mechanism 357 for the PA-SWNTs, which isconsistent with the previous findings(Chowdhury et al. 2012b, Jaisi 358 et al. 2008).

At $100 \mathrm{mM} \mathrm{NaCl}$, however, the amount of PA used in dispersing SWNTs demonstrates 360 significant influence on their transport behavior (Figure 2). The percent breakthrough of PA361 SWNTs increases with the increase in PA concentrations. The elution of 5\% PA-SWNTs is 362 found to be $92.9 \pm 3.3 \%$ compared to $29.1 \pm 6.4 \%$ for the $0.02 \%$ PA case. Percent eluted is 363 estimated as $57.4 \pm 8.6$ and $71 \pm 4.5$ for 0.1 and $1 \%$ PA, respectively. The increased mobility of 364 PA-SWNTs with the increase in PA concentration has likely resultedfrom a steric interaction 
365 between attached nonionic PA macromolecules on the SWNT surfaces (Saleh et al. 2010).

366 Enhanced transport via similar surface modification of SWNTs has been reported

367 earlier(Bouchard et al. 2012, Tian et al. 2012). The shape of the PA-SWNT breakthrough curves

368 at $100 \mathrm{mM} \mathrm{NaCl}$ is to be noted as it does not follow the tracer or other PA-SWNT transport

369 trends, but rather shows a gradual increase over time with no plateau at the end of the pulse

370 injection. Such behavior can be attributed to progressive blocking of available deposition sites as

371 described in earlier studies(Bradford and Bettahar 2006, Kasel et al. 2013). Continual injection

372 of PA-SWNTs blocks the available surface sites on the sand collectors via attachment of the

373 SWNTs over time. Thus subsequent PA-SWNT injection results in SWNT-SWNT interaction

374 between SWNTs in pore water and SWNTs that have already coated the collector grains. Longer

375 PV flushing causes complete recovery of these PA-SWNTs after 15 PV (Figure S9), when all 376 available deposition sites onto the collectors have been exhausted and been coated with the 377 SWNTs.

\subsection{Transport of AuNS \& PA-SWNT Hetero-dispersions}

379 The role of PA-SWNTs on AuNS transport is evaluated by performing transport experiments of AuNS-PA-SWNT hetero-dispersions. This scenario simulates coexistence of primary AuNS and secondary SWNTs in the pore water. SWNTs dispersed in 5\% PA solution were used to prepare

382 the hetero-dispersions (ensuring minimal surface interaction with PA-SWNTs). Figure 3 383 presents the breakthrough profiles (Figure 3a) and corresponding elution percentages (Figure 3b) 384 determined from the co-transport experiments. The maximum $\mathrm{C} / \mathrm{C}_{0}$ values (i.e., from $3850.99 \pm 0.007$ to $0.96 \pm 0.01$ ) and $\%$ eluted (i.e., $98.0 \pm 1.2 \%$ to $79.1 \pm 3.2 \%$ ) decrease with the increase 386 in $\mathrm{NaCl}$ concentration from $1 \mathrm{mM}$ to $100 \mathrm{mM}$. Though the strength of the electrolytes showed 387 minimal effect on the breakthrough plateau of the co-transport of AuNSs, the shape of the 
388 breakthrough profiles shows unique differences between high and low electrolyte conditions. 389 AuNS hetero-dispersion breakthrough shapes(Figure 3a) deviate from those of thehomo390 dispersion case (Figure 1a), but closely resembles the shapes of 5\% PA-SWNT breakthrough 391 (Figure 2a). The observed resemblances suggest that higher mobility of the AuNSs) is likely due 392 to their facilitated co-transport with highly mobile 5\% PA-SWNTs, even at high electrolyte 393 strength. The filtration of AuNSs likely has occurred via facilitated removal of PA-SWNTs, 394 where AuNSs nucleated around the PA-SWNTs at elevated ionic strength conditions. Similar 395 observations have been reported elsewhere for AuNS hetero-aggregation(Afrooz et al. 2013a). 396 Transport mechanisms describing similar enhanced mobility of titanium dioxide $\left(\mathrm{TiO}_{2}\right)$ in the 397 presence of CNTs have also been reported earlier(Wang et al. 2014). Such preferential 398 attachment of the negatively charged AuNSs onto the PA-SWNTs, instead of onto the collector 399 surfaces, can be explained by unfavorable electrostatic interaction between these surfaces (Figure 400 S6) - i.e., charged AuNSs and likely charged sand surfaces with $-40 \mathrm{mV}($ Johnson et al. 1996) to $401-25 \mathrm{mV}$ (Saiers and Lenhart 2003) surface potential at $10 \mathrm{mM}$ to $100 \mathrm{mM} \mathrm{NaCl}$ concentration402 compared to electrostatically favorable AuNS and PA-SWNT interaction (with PA-SWNT EPM 403 values of $-3.5 \mathrm{mV}$ to $-0.6 \mathrm{mV}$ at $1 \mathrm{mM}$ to $100 \mathrm{mM} \mathrm{NaCl}$ concentration). Furthermore, an order 404 of magnitude smaller size of the SWNTs (compared to sand grains) provides additional (by an 405 approx. factor of 1.5) surface area for the AuNSs to attach (Table S1 to S3). Release curves of the co-deposited AuNSs in the presence of 30 and $100 \mathrm{mM} \mathrm{NaCl}$ (no 407 release observed for 1 and $10 \mathrm{mM}$ cases) are presented in Figure S10. The AuNS \%releases 408 (Figure S8) are 59\% and 55\% for 30 and $100 \mathrm{mM}$ ionic strength, respectively. Comparison of 409 these release amounts with those of the homo-dispersion cases (Figure S7) suggests that the 410 presence of PA-SWNTs increases the irreversible attachment of the primary particles at high 
411 electrolyte concentrations. The mechanism of AuNS removal in hetero-dispersion cases is likely

412 physical filtration(Jaisi et al. 2008) of PA-SWNTs with attached AuNS particles on the SWNT

413 surfaces. Physical filtration of PA-SWNTsthrough the sand packed column has been described

414 in the in the transport behavior of PA-SWNT homo-dispersion: section 3.4 (Figure S8).

415

416

417

\subsection{Transport of AuNS through PA-SWNT Coated Sand}

418 The breakthrough curves (Figure 4) of AuNS homo-dispersions through PA-SWNTs $(0.02 \%$

419 PA) coated sand columns simulated pre-existing SWNTs in the porous media. Average elution 420 of AuNSs is found to be $94.4 \pm 4.5 \%$ and $90.3 \pm 3.5 \%$ for 1 and $10 \mathrm{mM} \mathrm{NaCl}$, respectively. The

421 mobility of the AuNSs decreases significantly at higher $\mathrm{NaCl}$ concentration, resulting in $42263.6 \pm 1.6 \%$ and $10.6 \pm 6.1 \%$ elution under 30 and $100 \mathrm{mM} \mathrm{NaCl}$, respectively. Comparing Figure 4234 (i.e., pre-coated sand condition) with Figure 1 (i.e., uncoated sand condition) reveals that the 424 AuNS breakthrough is strongly influenced by the presence of PA-SWNTs on the sand grains. 425 Average \% elution is lower for the pre-coated surfaces, but thisinfluence is minor at low ionic 426 strength. However, at $100 \mathrm{mM} \mathrm{NaCl}$ thesedifferences are profound, resulting in only $10.6 \pm 6.1 \%$ 427 of elution of the AuNSs through the pre-coated sand compared to $40.0 \pm 2.3 \%$ through uncoated 428 sand. Increased filtration of AuNSs through PA-SWNT coated sand surfaces supports the earlier 429 hypothesis regarding preferential attachment of the AuNSs onto the PA-SWNTs. AuNSs prefer 430 the PA-SWNT coated sand surfaces to the bare sand surfaces and thus exhibit higher filtration 431 for the pre-coated case. Similar enhanced filtration has been reported earlier for preferential 432 attachment of biological particles (i.e., E. coli) with CNTs in high electrolyte concentration(Yang 433 et al. 2013a). 


\subsection{Role of NOM on AuNS Transport}

436 The effect of NOM on AuNS transport was investigated for the AuNS homo-dispersion case

437 through PA-SWNT coated sand at ionic strength relevant to fresh water conditions. Thepresence

438 of SRHA $(2.5 \mathrm{mg} / \mathrm{L})$ shows minor enhancement in AuNS transport at $10 \mathrm{mM}$ ionic strength

439 (Figure 5); i.e., $91 \pm 3.25 \%$ and $83.5 \pm 2.5 \%$ AuNS elution with and without SRHA, respectively.

440 Low average molecular weight (MW) of SRHA [ 1490 Da (Wang et al. 2001)] in comparison to

441 both polymers (i.e., MW>5000 Da) suggests that replacement of adsorbed macromolecules by

442 SRHA is highly unlikely(Afrooz et al. 2013a), hence had little influence on particle-particle or 443 particle-collector interaction. Therefore, a slight increase in elution with SRHA thus is probably 444 resulted from SRHA adsorption onto the collector surfaces(Wei et al. 2014) resulting in 445 increased electrostatic repulsion, hence decreased filtration(Wang et al. 2015). It should be 446 noted here that the effect of NOM on the transport of hetero-dispersion of AuNS-PA-SWNT has 447 not been investigated in this study: SRHA is known to facilitate transport (Hyung and Kim 448 2008, Jaisi et al. 2008, Yang et al. 2013b), which is already very high for the hetero-dispersion 449 cases, thus might not show significant differences.

\section{Conclusions}

451 Interaction and transport of a primary ENM (e.g., AuNS) upon environmental release with a 452 secondary ENM (e.g., PA-SWNTs) is highly likely. Such interactions may occur while the 453 secondary particles are in suspension (co-transport) or are already deposited onto the porous 454 media (the collector surfaces are pre-coated). This study assesses both scenarios of filtration in 455 presence of $1,10,30$, and $100 \mathrm{mM} \mathrm{NaCl}$ conditions. The results indicate the following: 
472 473

76

- The presence of PA-SWNTs does not significantly alter filtration behavior of AuNSs at low ionic strength (equivalent to fresh pore-water conditions), AuNSs are significantly more mobile and thus will travel further in the porous media at elevated ionic strengths (e.g., in saline pore-water environment) when secondary particles (e.g., PA-SWNTs) coexist with the primary ones in the pore water.

- Increased mobility of AuNSs in the presence of PA-SWNTscan be attributed to the facilitated transport of AuNS;i.e., highly mobile PA-SWNTs act as carriersof the AuNSs.

- The pre-deposited SWNTs onto porous media will likely enhance filtration of AuNS at both low and high ionic strength conditions via facilitated removal.

- Experimental results estimate that transport distances (using CFT) of $0.1 \%$ AuNS (i.e., $\left.\mathrm{C} / \mathrm{C}_{0}=0.001\right)$ at $100 \mathrm{mM} \mathrm{NaCl}$ in homo-dispersion, hetero-dispersion, and pre-coated (with PA-SWNTs) are 0.6, 10.2, and $0.2 \mathrm{~m}$ respectively (Table S4), which signifies rather enhanced transport of the primary particulates in hetero-transport conditions.

- At fresh pore-water condition, the presence of NOM does nothave any significant influence on co-transport of AuNSs.

In reality, however, all of theseinfluences may become far more convoluted due to the added complexity of natural colloids and geo-macromolecules. ENM surface coatings and subsequent ligand exchange will also influence the transport behavior significantly. This is one of the first studies reporting co-transport of ENMs through porous media, and it highlights the importance of further research on such binary particulate conditions. 
This work was funded by the National Science Foundation (CBET1440261). We thank Jaime

Plazas-Tuttle (University of Texas at Austin) for making the TOC figure for this manuscript.

\section{References}

Afrooz, A.N., Khan, I.A., Hussain, S.M. and Saleh, N.B. (2013a) Mechanistic heteroaggregation of gold nanoparticles in a wide range of solution chemistry. Environmental Science \& Technology 47(4), 1853-1860.

Afrooz, A.R.M.N., Sivalapalan, S.T., Murphy, C.J., Hussain, S.M., Schlager, J.J. and Saleh, N.B. (2013b) Spheres vs. rods: The shape of gold nanoparticles influences aggregation and deposition behavior. Chemosphere 91(1), 93-98.

Bouchard, D., Zhang, W., Powell, T. and Rattanaudompol, U.-s. (2012) Aggregation kinetics and transport of single-walled carbon nanotubes at low surfactant concentrations. Environmental Science \& Technology 46(8), 4458-4465.

Bradford, S.A. and Bettahar, M. (2006) Concentration dependent transport of colloids in saturated porous media. Journal of Contaminant Hydrology 82(1), 99-117.

Bradford, S.A., Bettahar, M., Simunek, J. and Van Genuchten, M.T. (2004) Straining and attachment of colloids in physically heterogeneous porous media. Vadose Zone Journal 3(2), 384-394.

Bronikowski, M.J., Willis, P.A., Colbert, D.T., Smith, K. and Smalley, R.E. (2001) Gas-phase production of carbon single-walled nanotubes from carbon monoxide via the HiPco process: A parametric study. Journal of Vacuum Science \& Technology A 19(4), 18001805.

Cai, L., Tong, M., Ma, H. and Kim, H. (2013) Cotransport of titanium dioxide and fullerene nanoparticles in saturated porous media. Environmental Science \& Technology 47(11), 5703-5710.

Cai, L., Zhu, J., Hou, Y., Tong, M. and Kim, H. (2015) Influence of Gravity on Transport and Retention of Representative Engineered Nanoparticles in Quartz Sand. Journal of Contaminant Hydrology.

Cerbelaud, M., Videcoq, A., Abélard, P., Pagnoux, C., Rossignol, F. and Ferrando, R. (2008) Heteroaggregation between $\mathrm{A} 12 \mathrm{O} 3$ submicrometer particles and $\mathrm{SiO} 2$ nanoparticles: Experiment and simulation. Langmuir 24(7), 3001-3008.

Chang, X. and Bouchard, D.C. (2013) Multiwalled carbon nanotube deposition on model environmental surfaces. Environmental Science \& Technology 47(18), 10372-10380.

Chowdhury, I., Cwiertny, D.M. and Walker, S.L. (2012a) Combined factors influencing the aggregation and deposition of nano-TiO2 in the presence of humic acid and bacteria. Environmental Science \& Technology 46(13), 6968-6976. 
Chowdhury, I., Duch, M.C., Gits, C.C., Hersam, M.C. and Walker, S.L. (2012b) Impact of synthesis methods on the transport of single walled carbon nanotubes in the aquatic environment. Environmental Science \& Technology 46(21), 11752-11760.

El Badawy, A.M., Aly Hassan, A., Scheckel, K.G., Suidan, M.T. and Tolaymat, T.M. (2013) Key Factors Controlling the Transport of Silver Nanoparticles in Porous Media. Environmental Science \& Technology 47(9), 4039-4045.

Fresnais, J., Yan, M., Courtois, J., Bostelmann, T., Bée, A. and Berret, J.F. (2013) Poly(acrylic acid)-coated iron oxide nanoparticles: Quantitative evaluation of the coating properties and applications for the removal of a pollutant dye. Journal of Colloid and Interface Science 395(0), 24-30.

Georgakilas, V., Voulgaris, D., Vazquez, E., Prato, M., Guldi, D.M., Kukovecz, A. and Kuzmany, H. (2002) Purification of HiPCO carbon nanotubes via organic functionalization. Journal of the American Chemical Society 124(48), 14318-14319.

Godinez, I.G. and Darnault, C.J.G. (2011) Aggregation and transport of nano-TiO2 in saturated porous media: Effects of $\mathrm{pH}$, surfactants and flow velocity. Water Research 45(2), 839851.

Gottschalk, F. and Nowack, B. (2011) The release of engineered nanomaterials to the environment. Journal of Environmental Monitoring 13(5), 1145-1155.

He, F., Zhang, M., Qian, T. and Zhao, D. (2009) Transport of carboxymethyl cellulose stabilized iron nanoparticles in porous media: Column experiments and modeling. Journal of Colloid and Interface Science 334(1), 96-102.

Hong, Y., Honda, R.J., Myung, N.V. and Walker, S.L. (2009) Transport of Iron-Based Nanoparticles: Role of Magnetic Properties. Environmental Science \& Technology 43(23), 8834-8839.

Hotze, E.M., Phenrat, T. and Lowry, G.V. (2010) Nanoparticle aggregation: challenges to understanding transport and reactivity in the environment. Journal of environmental quality 39(6), 1909-1924.

Huynh, K.A., McCaffery, J.M. and Chen, K.L. (2012) Heteroaggregation of multiwalled carbon nanotubes and hematite nanoparticles: Rates and mechanisms. Environmental Science \& Technology 46(11), 5912-5920.

Hyung, H. and Kim, J.-H. (2008) Natural organic matter (NOM) adsorption to multi-walled carbon nanotubes: effect of NOM characteristics and water quality parameters. Environmental Science \& Technology 42(12), 4416-4421.

Jaisi, D.P., Saleh, N.B., Blake, R.E. and Elimelech, M. (2008) Transport of single-walled carbon nanotubes in porous media: filtration mechanisms and reversibility. Environmental Science \& Technology 42(22), 8317-8323.

Johnson, P.R., Sun, N. and Elimelech, M. (1996) Colloid transport in geochemically heterogeneous porous media: Modeling and measurements. Environmental Science \& Technology 30(11), 3284-3293.

Joo, S.H., Al-Abed, S.R. and Luxton, T. (2009) Influence of Carboxymethyl Cellulose for the Transport of Titanium Dioxide Nanoparticles in Clean Silica and Mineral-Coated Sands. Environmental Science \& Technology 43(13), 4954-4959.

Kasel, D., Bradford, S.A., Šimůnek, J., Heggen, M., Vereecken, H. and Klumpp, E. (2013) Transport and retention of multi-walled carbon nanotubes in saturated porous media: Effects of input concentration and grain size. Water Research 47(2), 933-944. 
Khin, M.M., Nair, A.S., Babu, V.J., Murugan, R. and Ramakrishna, S. (2012) A review on nanomaterials for environmental remediation. Energy \& Environmental Science 5(8), 8075-8109.

Kim, H.-J., Phenrat, T., Tilton, R.D. and Lowry, G.V. (2012) Effect of kaolinite, silica fines and $\mathrm{pH}$ on transport of polymer-modified zero valent iron nano-particles in heterogeneous porous media. Journal of Colloid and Interface Science 370, 1-10.

Köhler, A.R., Som, C., Helland, A. and Gottschalk, F. (2008) Studying the potential release of carbon nanotubes throughout the application life cycle. Journal of Cleaner Production 16(8), 927-937.

Li, Z., Sahle-Demessie, E., Hassan, A.A. and Sorial, G.A. (2011) Transport and deposition of $\mathrm{CeO} 2$ nanoparticles in water-saturated porous media. Water Research 45(15), 44094418.

Lowry, G.V., Gregory, K.B., Apte, S.C. and Lead, J.R. (2012) Transformations of nanomaterials in the environment. Environmental Science \& Technology 46(13), 6893-6899.

Mattison, N.T., O'Carroll, D.M., Rowe, R.K. and Petersen, E.J. (2011) Impact of Porous Media Grain Size on the Transport of Multi-walled Carbon Nanotubes. Environmental Science \& Technology 45(22), 9765-9775.

Moore, V.C., Strano, M.S., Haroz, E.H., Hauge, R.H., Smalley, R.E., Schmidt, J. and Talmon, Y. (2003) Individually suspended single-walled carbon nanotubes in various surfactants. Nano Letters 3(10), 1379-1382.

Nowack, B., Ranville, J.F., Diamond, S., Gallego-Urrea, J.A., Metcalfe, C., Rose, J., Horne, N., Koelmans, A.A. and Klaine, S.J. (2012) Potential scenarios for nanomaterial release and subsequent alteration in the environment. Environmental Toxicology and Chemistry 31(1), 50-59.

Petosa, A.R., Jaisi, D.P., Quevedo, I.R., Elimelech, M. and Tufenkji, N. (2010) Aggregation and deposition of engineered nanomaterials in aquatic environments: role of physicochemical interactions. Environmental Science \& Technology 44(17), 6532-6549.

Phenrat, T., Kim, H.-J., Fagerlund, F., Illangasekare, T., Tilton, R.D. and Lowry, G.V. (2009) Particle Size Distribution, Concentration, and Magnetic Attraction Affect Transport of Polymer-Modified Fe-0 Nanoparticles in Sand Columns. Environmental Science \& Technology 43(13), 5079-5085.

Quevedo, I.R. and Tufenkji, N. (2009) Influence of solution chemistry on the deposition and detachment kinetics of a CdTe quantum dot examined using a quartz crystal microbalance. Environmental Science \& Technology 43(9), 3176-3182.

Saiers, J.E. and Lenhart, J.J. (2003) Ionic-strength effects on colloid transport and interfacial reactions in partially saturated porous media. Water Resources Research 39(9), 1256.

Saiers, J.E. and Ryan, J. (2005) Colloid deposition on non-ideal porous media: The influences of collector shape and roughness on the single-collector efficiency. Geophysical research letters 32(21).

Saleh, N., Sirk, K., Liu, Y., Phenrat, T., Dufour, B., Matyjaszewski, K., Tilton, R.D. and Lowry, G.V. (2007) Surface modifications enhance nanoiron transport and NAPL targeting in saturated porous media. Environmental Engineering Science 24(1), 45-57.

Saleh, N.B., Pfefferle, L.D. and Elimelech, M. (2008) Aggregation kinetics of multiwalled carbon nanotubes in aquatic systems: measurements and environmental implications. Environmental Science \& Technology 42(21), 7963-7969. 
Saleh, N.B., Pfefferle, L.D. and Elimelech, M. (2010) Influence of Biomacromolecules and Humic Acid on the Aggregation Kinetics of Single-Walled Carbon Nanotubes. Environmental Science \& Technology 44(7), 2412-2418.

Soejima, T., Oshiro, S., Nakatsuji, Y. and Ito, S. (2011) Dense aqueous colloidal gold nanoparticles prepared from highly concentrated precursor solution. Journal of Colloid and Interface Science 362(2), 325-329.

Song, L. and Elimelech, M. (1994) Transient Deposition of Colloidal Particles in Heterogeneous Porous Media. Journal of Colloid and Interface Science 167(2), 301-313.

Song, L., Johnson, P.R. and Elimelech, M. (1994) Kinetics of Colloid Deposition onto Heterogeneously Charged Surfaces in Porous Media. Environmental Science \& Technology 28(6), 1164-1171.

Thio, B.J.R., Zhou, D. and Keller, A.A. (2011) Influence of natural organic matter on the aggregation and deposition of titanium dioxide nanoparticles. Journal of Hazardous Materials 189(1-2), 556-563.

Tian, Y., Gao, B., Morales, V.L., Wang, Y. and Wu, L. (2012) Effect of surface modification on single-walled carbon nanotube retention and transport in saturated and unsaturated porous media. Journal of Hazardous Materials 239, 333-339.

Tong, M., Ding, J., Shen, Y. and Zhu, P. (2010) Influence of biofilm on the transport of fullerene (C-60) nanoparticles in porous media. Water Research 44(4), 1094-1103.

Tripathi, S., Champagne, D. and Tufenkji, N. (2011) Transport Behavior of Selected Nanoparticles with different Surface Coatings in Granular Porous Media coated with Pseudomonas aeruginosa Biofilm. Environmental Science \& Technology 46(13), 69426949.

Vaisman, L., Wagner, H.D. and Marom, G. (2006) The role of surfactants in dispersion of carbon nanotubes. Advances in colloid and interface science 128, 37-46.

Wang, D., Jin, Y. and Jaisi, D.P. (2015) Effect of Size Selective Retention on the Cotransport of Hydroxyapatite and Goethite Nanoparticles in Saturated Porous Media. Environmental Science \& Technology.

Wang, X., Cai, L., Han, P., Lin, D., Kim, H. and Tong, M. (2014) Cotransport of multi-walled carbon nanotubes and titanium dioxide nanoparticles in saturated porous media. Environmental pollution 195, 31-38.

Wang, Y., Combe, C. and Clark, M.M. (2001) The effects of $\mathrm{pH}$ and calcium on the diffusion coefficient of humic acid. J. Membr. Sci. 183(1), 49-60.

Wang, Y., Gao, B., Morales, V.L., Tian, Y., Wu, L., Gao, J., Bai, W. and Yang, L. (2012) Transport of titanium dioxide nanoparticles in saturated porous media under various solution chemistry conditions. Journal of Nanoparticle Research 14(9), 1-9.

Wei, X., Shao, M., Du, L. and Horton, R. (2014) Humic acid transport in saturated porous media: Influence of flow velocity and influent concentration. Journal of Environmental Sciences 26(12), 2554-2561.

Xin, J., Tang, F., Zheng, X., Shao, H. and Kolditz, O. (2016) Transport and retention of xanthan gum-stabilized microscale zero-valent iron particles in saturated porous media. Water Research 88, 199-206.

Yang, H., Tong, M. and Kim, H. (2013a) Effect of Carbon Nanotubes on the Transport and Retention of Bacteria in Saturated Porous Media. Environmental Science \& Technology 47(20), 11537-11544. 
Yang, J., Bitter, J.L., Smith, B.A., Fairbrother, D.H. and Ball, W.P. (2013b) Transport of oxidized multi-walled carbon nanotubes through silica based porous media: Influences of aquatic chemistry, surface chemistry, and natural organic matter. Environmental Science \& Technology 47(24), 14034-14043.

\section{List of Figure Captions:}

FIGURE 1.Transport of AuNS homo-dispersion. a) breakthrough and b) \% elution. 4 PV of 12.5 $\mathrm{mg} / \mathrm{L}$ AuNS pulses were injected through the sand packed column at a flow velocity of $12 \mathrm{~cm} / \mathrm{h}$. The error bars represent 1 standard deviation between measured values.

FIGURE 2.Transport of PA-SWNT homo-dispersion at $100 \mathrm{mM} \mathrm{NaCl}$ as a function of PA surface modification. a) breakthrough profiles and b) \% elution. 4 PV of $10 \mathrm{mg} / \mathrm{L}$ PA-SWNT pulses were injected through the sand packed column at a flow velocity of $12 \mathrm{~cm} / \mathrm{h}$. The error bars represent 1 standard deviation between measured values.

FIGURE 3.Transport of AuNS- SWNT hetero-dispersions. a) breakthrough and b) \% elution. 4 PV of hetero-dispersion, i.e., $12.5 \mathrm{mg} / \mathrm{L}$ AuNS and $2.5 \mathrm{mg} / \mathrm{L} \mathrm{PA-SWNT} \mathrm{pulses} \mathrm{were} \mathrm{injected}$ through the sand packed column at a flow velocity of $12 \mathrm{~cm} / \mathrm{h}$. The error bars represent 1 standard deviation between measured values.

FIGURE 4. Transport of AuNS homo-dispersion through SWNT-coated sand column. a) breakthrough curvesand b) percent transport. A 4 PV of AuNS $(12.5 \mathrm{mg} / \mathrm{L})$ pulse was injected through the PA-SWNT coated sand column at $12 \mathrm{~cm} / \mathrm{h}$ of flow velocity. An equal volume of pulse of $2.5 \mathrm{mg} / \mathrm{L} \mathrm{PA}-\mathrm{SWNT}(0.02 \% \mathrm{PA})$ suspension was used for coating the sand at the same flow velocity. The error bars represent 1 standard deviation between measured values.

FIGURE 5. Transport of AuNS homo-dispersion through SWNT-coated sand column at $10 \mathrm{mM}$ $\left(7 \mathrm{mM} \mathrm{NaCl}+0.75 \mathrm{mM} \mathrm{CaCl}_{2}\right.$ ) ionic strength and with and without the presence of $2.5 \mathrm{mg} / \mathrm{L}$ SRHA. a) breakthrough curvesand b) \% elution. Sand was coated with a 4 PV pulse of $2.5 \mathrm{mg} / \mathrm{L}$ PA-SWNT (0.02\% PA). Following this step, 4 PV pulse of $12.5 \mathrm{mg} / \mathrm{L}$ AuNS with and without SRHA were injected through the pre-coated sand. The flow velocity for all cases was 12 $\mathrm{cm} / \mathrm{h}$. The error bars represent 1 standard deviation between measured values. 
701

702

703

704

\section{Graphical Abstract:}

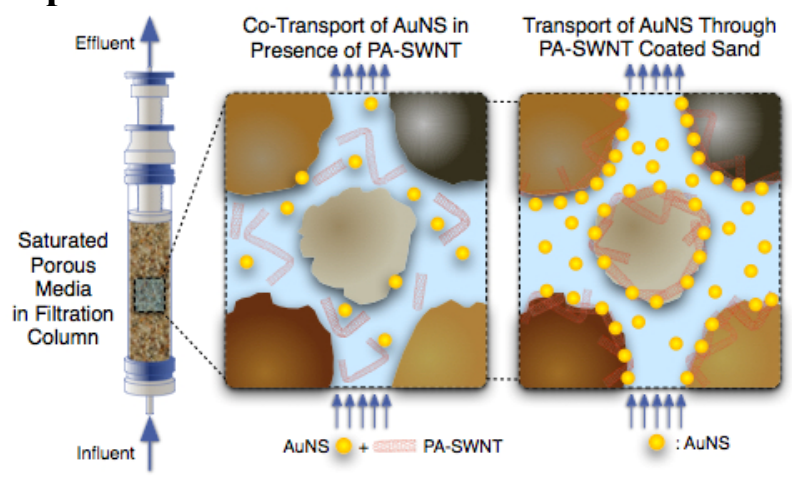

706

707

708

709

710

711

712

713

714

715

716

717

718

719

720

721

722

723 

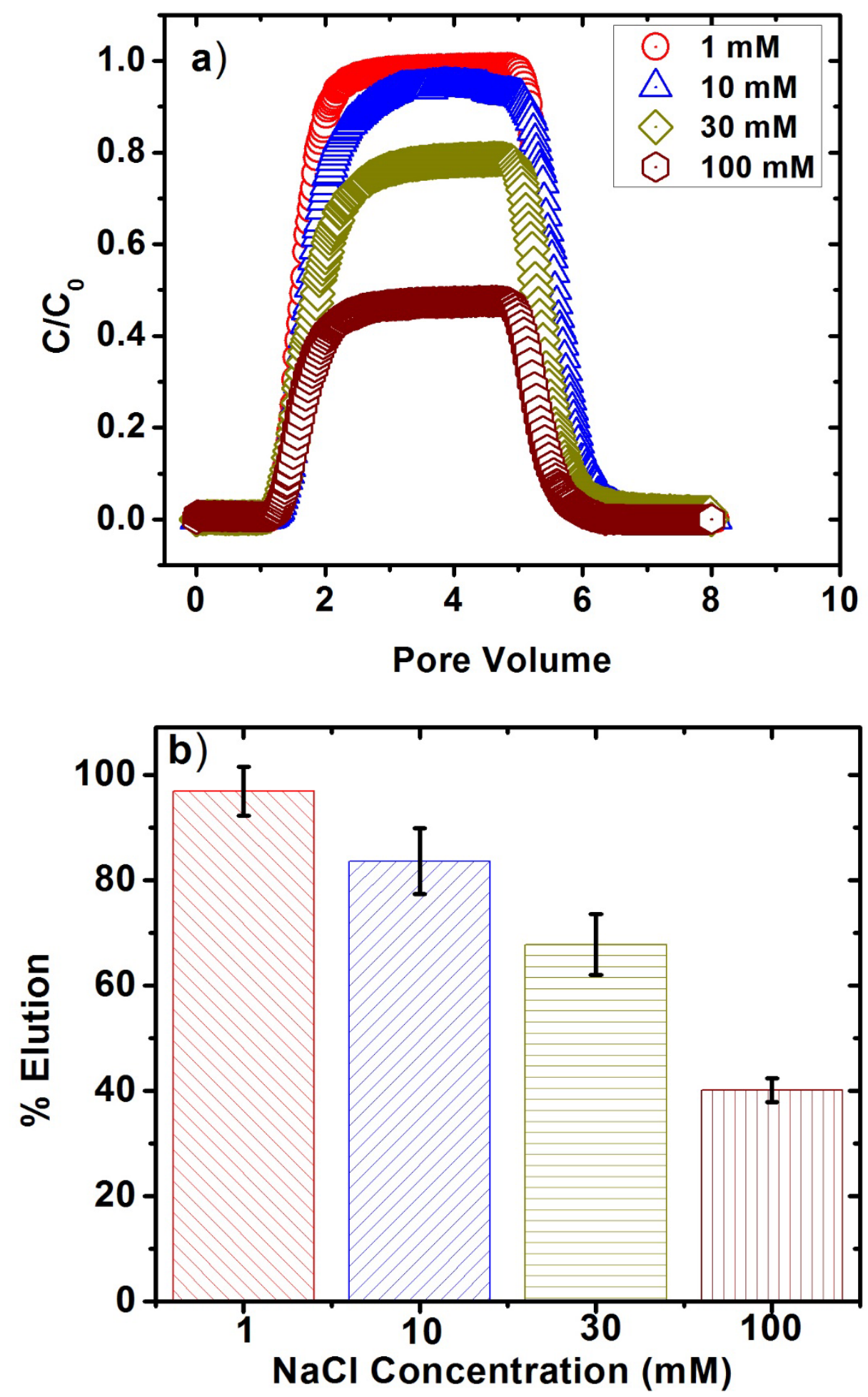

FIGURE 1.Transport of AuNS homo-dispersion. a) breakthrough and b) \% elution. 4 PV of 12.5 $728 \mathrm{mg} / \mathrm{L}$ AuNS pulses were injected through the sand packed column at a flow velocity of $12 \mathrm{~cm} / \mathrm{h}$. 729 The error bars represent 1 standard deviation between measured values. 

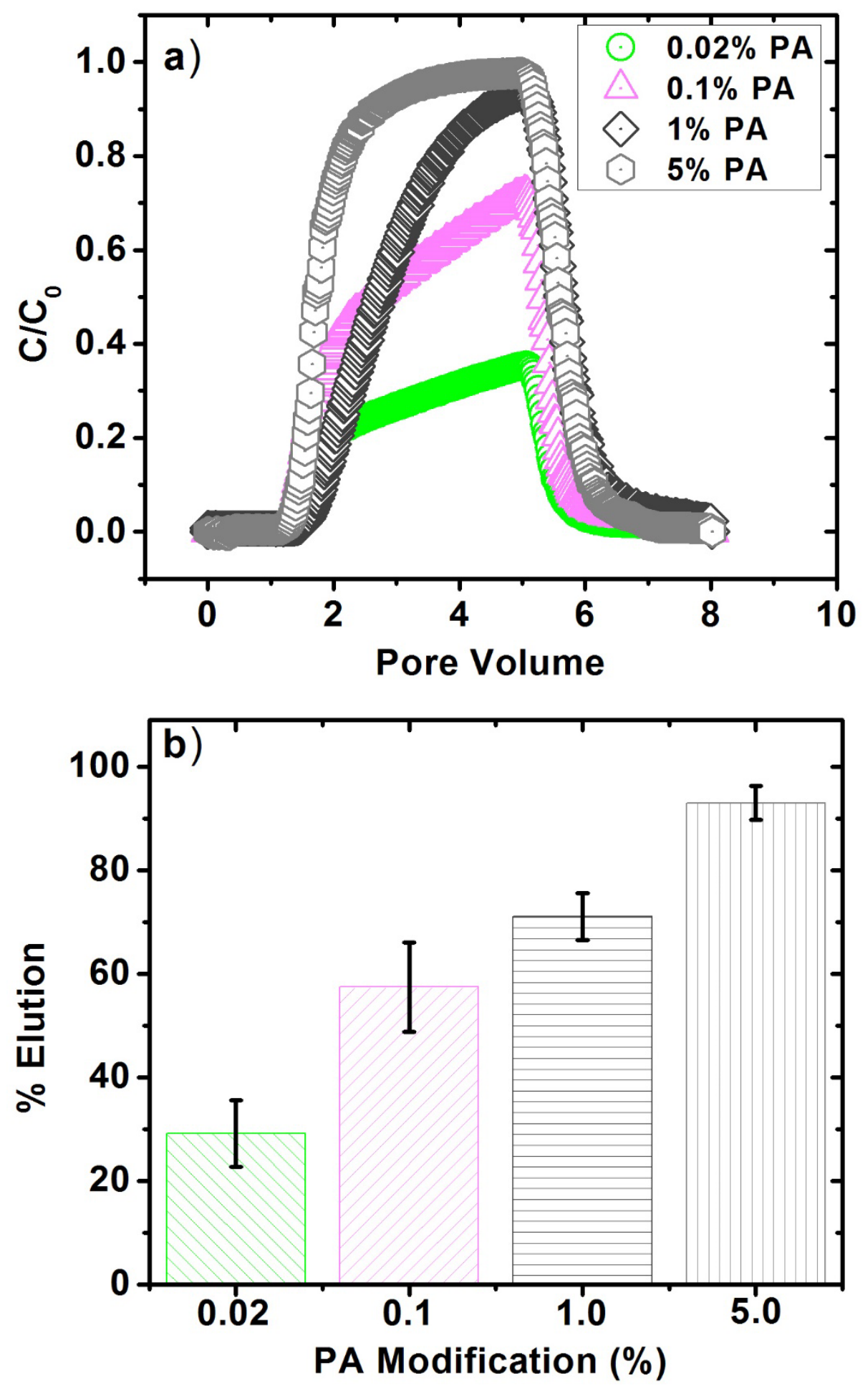

FIGURE 2.Transport of PA-SWNT homo-dispersion at $100 \mathrm{mM} \mathrm{NaCl}$ as a function of PA surface modification. a) breakthrough profiles and b) \% elution. $4 \mathrm{PV}$ of $10 \mathrm{mg} / \mathrm{L}$ PA-SWNT pulses were injected through the sand packed column at a flow velocity of $12 \mathrm{~cm} / \mathrm{h}$. The error bars represent 1 standard deviation between measured values. 


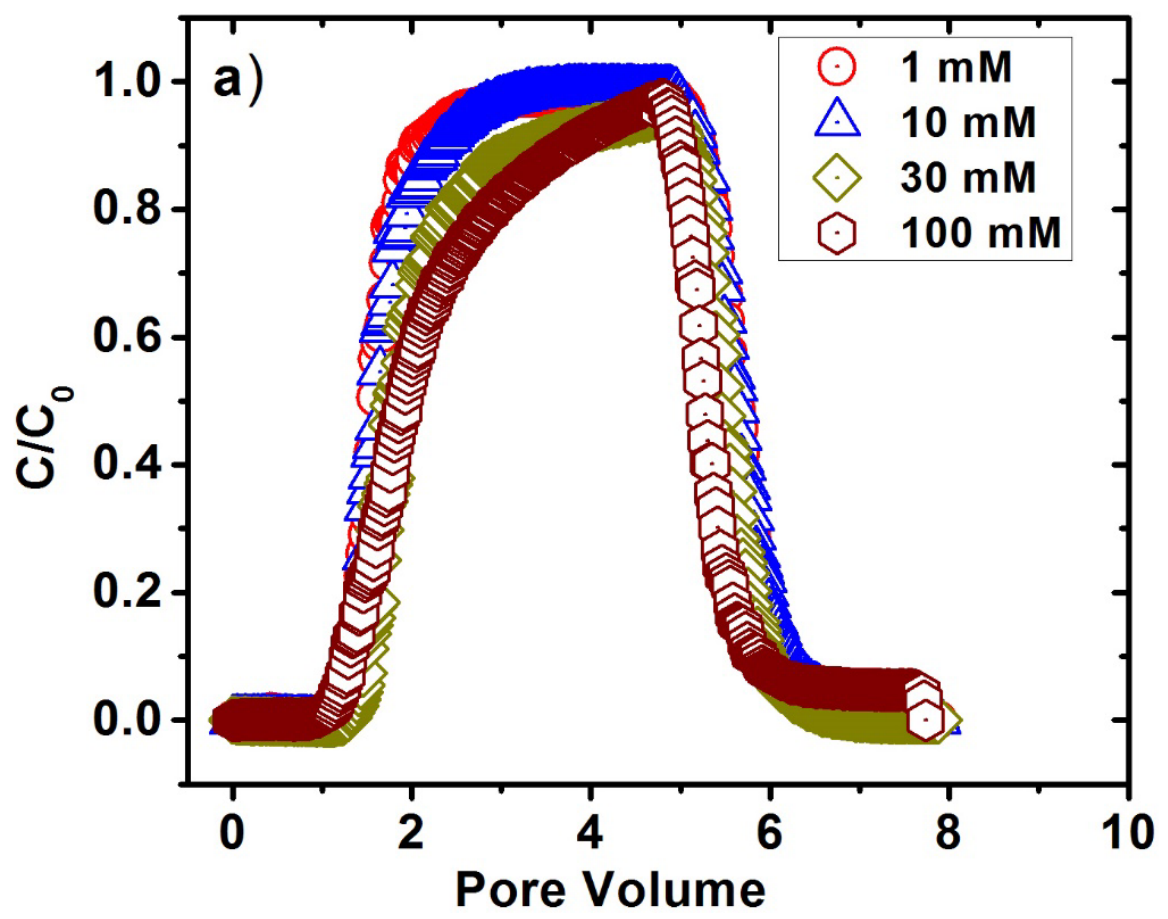

739

740

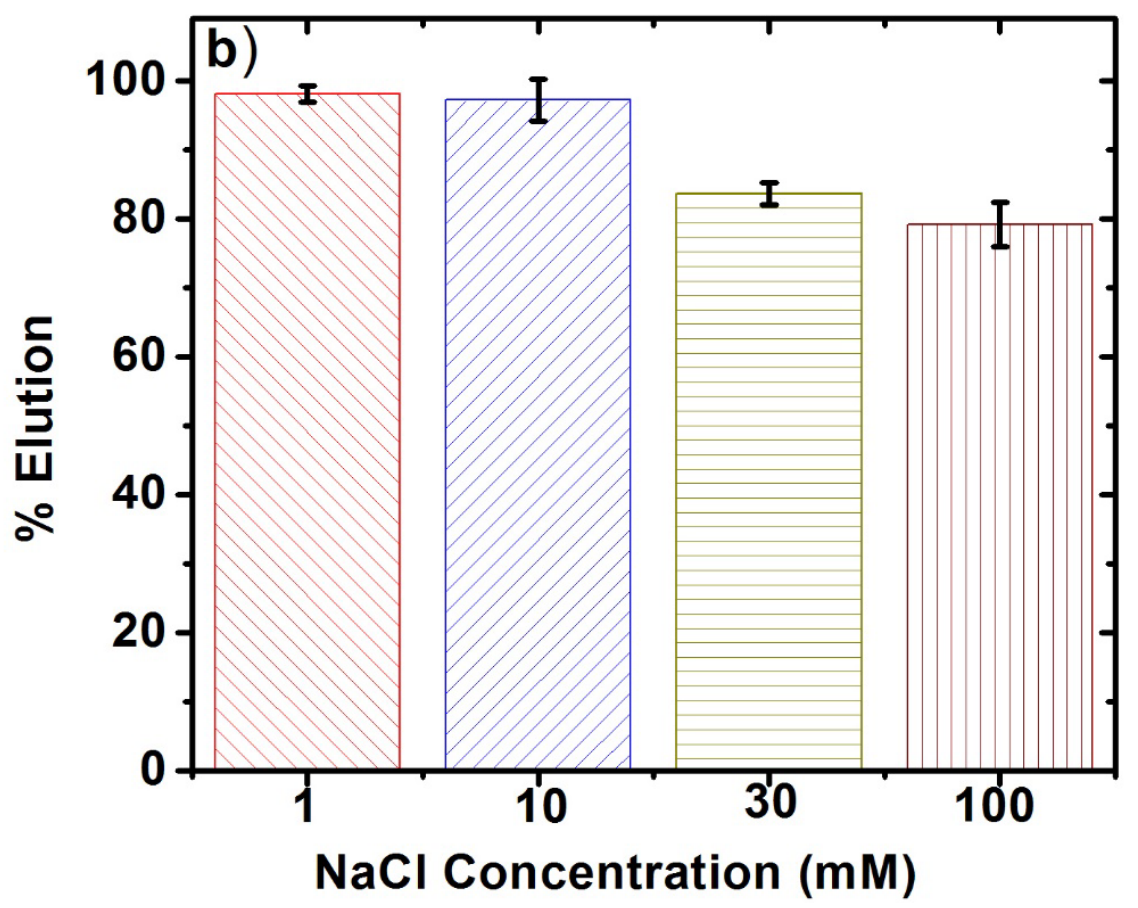

741 FIGURE 3.Transport of AuNS- SWNT hetero-dispersions. a) breakthrough and b) \% elution. 4 742 PV of hetero-dispersion, i.e., $12.5 \mathrm{mg} / \mathrm{L}$ AuNS and $2.5 \mathrm{mg} / \mathrm{L}$ PA-SWNT pulses were injected 743 through the sand packed column at a flow velocity of $12 \mathrm{~cm} / \mathrm{h}$. The error bars represent 1 744 standard deviation between measured values. 

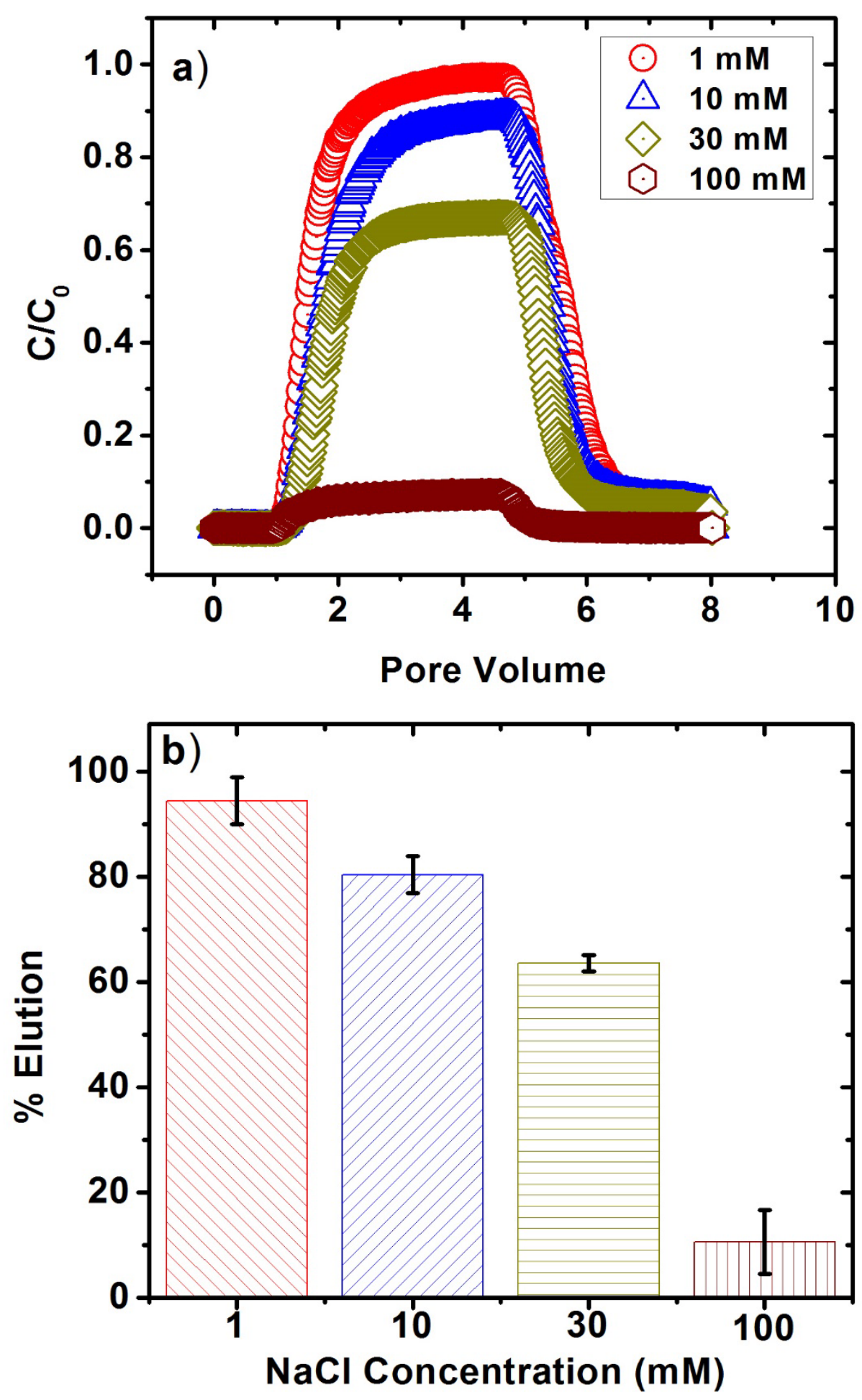

FIGURE 4. Transport of AuNS homo-dispersion through SWNT-coated sand column. a) breakthrough curvesand b) percent transport. A 4 PV of AuNS (12.5 mg/L) pulse was injected 751 through the PA-SWNT coated sand column at $12 \mathrm{~cm} / \mathrm{h}$ of flow velocity. An equal volume of 752 pulse of $2.5 \mathrm{mg} / \mathrm{L}$ PA-SWNT (0.02\% PA) suspension was used for coating the sand at the same 753 flow velocity. The error bars represent 1 standard deviation between measured values. 

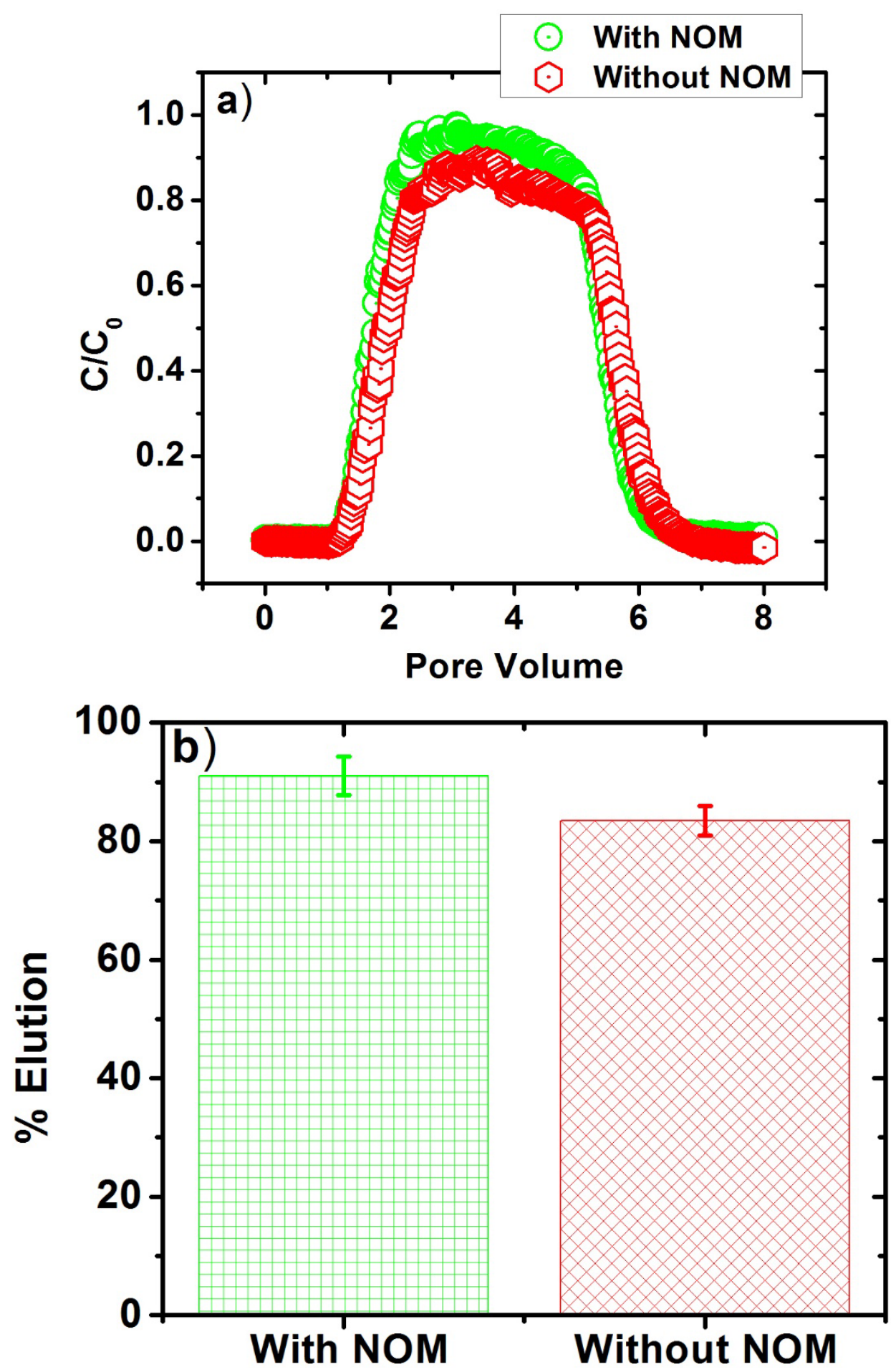

FIGURE 5. Transport of AuNS homo-dispersion through SWNT-coated sand column at $10 \mathrm{mM}$ $\left(7 \mathrm{mM} \mathrm{NaCl}+0.75 \mathrm{mM} \mathrm{CaCl}_{2}\right.$ ) ionic strength and with and without the presence of $2.5 \mathrm{mg} / \mathrm{L}$ SRHA. a) breakthrough curvesand b) \% elution. Sand was coated with a 4 PV pulse of $2.5 \mathrm{mg} / \mathrm{L}$ PA-SWNT (0.02\% PA). Following this step, 4 PV pulse of $12.5 \mathrm{mg} / \mathrm{L}$ AuNS with and without SRHA were injected through the pre-coated sand. The flow velocity for all cases was 12 $\mathrm{cm} / \mathrm{h}$. The error bars represent 1 standard deviation between measured values. 